\title{
How to Say What You Mean and Mean What You Say
}

\author{
COMMUNICATION CORNER
}

\author{
by Philip Yaffe
}

\section{Editor's Introduction}

Each "Communication Corner" essay is self-contained; however, they build on each other. For best results, before reading this essay and doing the exercise, go to the first essay "How an Ugly Duckling Became a Swan," then read each succeeding essay. 


\title{
How to Say What You Mean and Mean What You Say
}

\author{
COMMUNICATION CORNER
}

\section{by Philip Yaffe}

If you remember your high-school grammar lessons, you may have it engraved on your mind that the fundamental building block of any good text is the paragraph. It isn't. It's not even the sentence. It's each individual word.

True, a single word by itself says very little; it has to be put together with other words into a sentence for it to have much meaning. However, if it is the wrong word or a weasel (imprecise) word, the sentence around it will not save it.

Let's look at an example.

As an undergraduate at UCLA, I tutored in writing. In the mid-1960s most universities hadn't yet established writing centers to rescue floundering students, so about the only way to get help was through private lessons.

I remember one case in particular. A girl came to me with a note from her professor, saying, "Young lady, I advise you either to drop my class immediately or prepare to fail it." Obviously she was bright enough; after all, she was a student at UCLA. So where was the problem? I read a couple of her papers that had gotten such poor marks. There was no question that she had a lot of interesting things to say. Equally, there was no question that she was saying them very badly.

It quickly became apparent where the problem lay. She wasn't consistently applying one of the fundamental principles of good writing, because she thought it was just too much trouble. It took a couple of sessions to convince her that it wasn't too much trouble-in fact it was crucial. Her writing immediately began to improve. At the end of the term, not only did she pass the class, she pulled her grade all the way up from an almost certain " $F$ " to a solid "B."

What was this fundamental principle that was causing her so much trouble? Precision. While she had the mind of a young adult (and a superior mind at that), she had the vocabulary of a child. Either the words she chose to use didn't fit what she was trying to say because they were too imprecise. Or she would use a whole phrase to say what could have been better said in a single word-had she only known the word, which she didn't. 
During our first session, I asked her, "When you are reading and come across a word you don't know, what do you do?" Her response was, "I can usually understand the sentence without it, so I just read past it. Besides, if I don't know a word, chances are I will never see it again, so looking it up in a dictionary would be a waste of time."

Expanding one's vocabulary is never a waste of time. However simply saying this to her probably would have had no effect. So I set her a challenge. "Over the coming week in your reading of newspapers, magazines, novels, etc., make a note of the most exotic word you can find and tell me what it is." "Is that all?" she queried? "Yes, that's all."

When she came back, she told me the word. I don't remember what it was, but to me it didn't seem exotic at all. So I set her a new challenge: "Over the next week, how many times do you think you will see this word again?" "I don't think I will ever see it again," she replied. "I bet you will see it at least 10 times," I said.

She probably thought I was crazy. However, the following week when I asked her how many times she had seen the word, she went all red in the face. Almost in disbelief, she said, "Fourteen times. I saw it 14 times!" "So from now on when you come across a word you don't know, what are you going to do?" "I'm going to look it up in the dictionary," she replied. And she did.

Let's not exaggerate. It isn't necessary to immediately look up every new word the moment you come across it. Building vocabulary doesn't happen instantaneously; it takes time. Moreover, occasionally using a less than precise word (le mot juste, as they say in French) will not sink your entire text; however, repeated use of imprecise words will.

True, you may sometimes wish to purposely use an imprecise word or phrase for reasons of style or emphasis. However, this should always be a conscious decision-dictated by reason, not ignorance.

\section{How to Construct Truly Effective Sentences}

Although individual words are the fundamental building blocks of a text, they are not its fundamental logical unit. As suggested earlier, that is the function of the sentence. Only when words are properly put into sentences can they convey anything but than their strict dictionary definition. Words in sentences also do something infinitely more important. Properly used, they clearly convey what the author is truly trying to say. Improperly used, they either fail to convey what the author is truly trying to say, or they convey something other than what the author means. 
So how do you construct truly effective sentences, time after time after time? There is no magic formula, but here some key suggestions.

\section{- Approach each sentence with the appropriate attitude.}

If you know what you are trying to achieve when constructing a sentence, you are more likely to achieve it. I think this was best said by famed essayist and novelist Robert Louis Stevenson (Kidnapped, Treasure Island, The Strange Case of Dr. Jekyll and Mr. Hyde): "Don't write merely to be understood. Write so that you cannot possibly be misunderstood."

Don't be too concerned about getting it right the first time

Stopping to analyze each sentence as you write it, then immediately revising it, is both unnecessary and counterproductive. Keep the objective in mind when you are writing the sentence; however, when you finish one sentence, immediately go on to the next one.

The appropriate time to revise is after you have completed the entire text. All well-written texts require at least two separate drafts. The primary objective of the first draft is to get down all your relevant information in a reasonably comprehensible form. The primary objective of the second draft is to convert "reasonably comprehensible" into "fully comprehensible." Revising each sentence immediately after writing it will continually break your flow of ideas. You may end up with a lot of perfectly formed sentences, but your text is still likely to be confused, rambling, and tedious.

- Fully benefit from the two hot spots in every sentence you write.

Hot spots? Yes. You may never have noticed it, but words at the beginning and at the end of a sentence have stronger emphasis than those in the middle. Therefore, by putting important information into these key locations, you aid reader comprehension.

Here's an example to demonstrate how hot spots work. While considering the following three sentences, bear in mind that hot spots don't have equal value. In general, the one at the end of a sentence is somewhat more forceful than the one at the beginning.

A. Astronomers searching for evidence of life outside of our solar system announced discovery of a new class of planets yesterday.

B. Yesterday astronomers searching for evidence of life outside of our solar system announced discovery of a new class of planets.

C. Astronomers searching for evidence of life outside of our solar system yesterday announced discovery of a new class of planets.

I hope you will agree that sentence A says what it has to say. But sentence B is better. And sentence $C$ is best of all. Why? 
In sentence A, we see that "yesterday," the time of the announcement, is in the hot spot at the end of the sentence. However, knowing when the announcement was made is hardly as important as the announcement itself. Moving "yesterday" to the hot spot at the beginning in sentence $B$ somewhat helps, but the time of the announcement is still very much a detail.

Sentence C puts "yesterday" in the middle, where such a minor detail belongs. This leaves the hot spots at the beginning and the end free to convey truly key information.

If following these suggestions sounds like a lot of work, it is. Good writing isn't easy, but it becomes easier with practice. And it provides significant rewards. In addition to Robert Louis Stevenson's dictum, here are a couple of other thoughts you may wish to keep in mind.

"Don't write merely to be understood. Write so that you cannot possibly be misunderstood." - Robert Louis Stevenson

"Nothing is more satisfying than to write a good sentence. It is no fun to write lumpish, dull prose the reader must plod through like wet sand." - Barbara Tuchman

"The writer does the greatest good who gives his reader the most knowledge and takes from him the least time." - Sydney Smith

Amen.

\section{Mathematical Magic}

In the previous installment, I showed you a simple and (to some) astonishing card trick. If you haven't figured out how it works, please read the explanation below.

\section{Remember the Procedure}

From a standard deck of 52 cards (no jokers), let the participant select any nine cards at random. Have the participant mix the cards any way he wants and hand them to you face down. Put the remaining cards aside; they will not be used.

On a table, deal out the cards face down into three piles of three cards each. Have the participant select two of the piles. Remove these two piles and stack them face down one on top of the other on the table. The table will have now one pile of three cards and one pile of six cards.

With your back turned, have the participant look at the bottom card of the three-card pile and remember it. Let's say this card is the five of spades. Place this pile face down on top of the sixcard pile. Now say: 
"Let's test your honesty. I'm going to ask you what card you saw. You can tell me the truth or tell me a lie, whichever you prefer. In other words, you can tell me what card you really saw or you can pretend you saw a different card. Either way, the cards themselves will reveal whether you are telling the truth or telling a lie."

Let's say the participant lies and claims the card he saw was the King of Hearts. Pick up the pile of the nine face down cards. Spell out the name of card he claimed he saw by dealing from your hand on to the table one card face down for each letter in the name of his card, in this case K-IN-G.

Place the remaining cards in your hand face down on top of cards now on the table. Pick up this pile of cards and deal out two cards face down for O-F. Place the remaining cards in your hand face down on top of those now on the table.

Pick up this pile of cards. Finally, deal out face down the suit of the claimed card on to the table. In this case, you deal out six cards for H-E-A-R-T-S. Place the cards remaining in your hand face down on top of this pile on the table.

Pick up the pile and say:

"You claim that the card you saw was the King of Hearts, right? Now let's see if you were telling the truth."

From the cards in your hand, deal out on to the table five cards for T-R-U-T-H. Deal out the first four cards face down. When you come to the fifth card, turn it face up. This will be the card the participant actually saw, in this case the Five of Spades. Now say:

"Oh, I see are not very truthful. Isn't this the card you really saw, not the one you told me you saw?"

He will have to admit that he had been untruthful and told you the wrong card.

What if he had told the truth, i.e. the card he said he saw really was the card he saw? That's easy. Simply say:

"Oh, I see you are a very honest person. You told the truth. This really is the card you saw, right?"

The trick works every time. The only thing you have to remember is: Always put the cards remaining in your hand on top of the cards already on the table. That's it. There is nothing more. 


\section{Here's The Secret}

Suppose you have nine cards in your hand, which you deal out face down into a pile on the table. The first card you deal out from your hand will become the ninth card in the pile you are building on the table, the second card you deal out from your hand will become the eighth card in the pile on the table, and so on. In other words, you get a pattern like this:

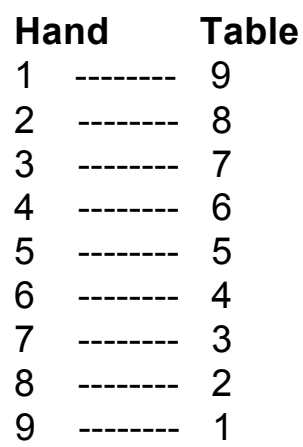

Note that card no. 5 in your hand also becomes card no. 5 in the pile on the table. No matter what that card is, card no. 5 in your hand will always be card no. 5 on the table. The trick works by maneuvering the card seen by the participant to become card no. 5 in the pile, so that when you spell out T-R-U-T-H, which has five letters, this is the card you will turn over.

In the example, the participant lies and claims that the card he saw was the king of hearts when in fact it was the five of spades. You deal out K-I-N-G on to the table and then cover these with the cards remaining in you hand. You know that whatever the selected card is, it must now be the third card from the bottom of the pile on the table, i.e. card no. 3 in your hand becomes card no. 7 on the table.

You pick up the pile and deal out O-F on to the table, then cover these cards with the cards remaining in your hand. Since the selected card was card no. 7 in the pile on the table, when you deal out two cards for O-F and then cover them with the cards remaining in your hand, you know that the selected card has moved up to be card no. 5 in the pile on the table.

You pick up the pile and deal out H-E-A-R-T-S on to the table, then cover these with the cards remaining in your hand. Since the selected card was card no. 5 in your hand, it must also be card no. 5 in the pile on the table.

Finally, you pick up the pile on the table and deal out T-R-U-T-H. You deal out the first four cards (T-R-U-T) face down. When you deal out card no. $5(\mathrm{H})$, you turn it face up. This will be the card the participant actually saw, no matter what he told you it was.

Graphically, the procedure looks like this ( $X$ represents the selected card). 
1. You deal out on to the table the name of the card (at least three letters) and put the remaining cards on top $(0,0,0,0,0,0, X, 0,0)$. The selected card is now card no. 7 in the pile on the table.

2. You deal out two cards for $\mathrm{O}-\mathrm{F}$ and put the remaining cards on top $(0,0,0,0, \mathrm{X}, 0,0,0,0)$. The selected card is now card no. 5 in the pile on the table.

3. You deal out the name of the suit (at least five letters) and put the reaming cards on top $(0,0,0,0, X, 0,0,0,0)$. The selected card remains card no. 5 in the pile.

4. You deal out the word T-R-U-T-H, which is five letters, leading you to card no. 5, the selected card.

\section{Cultural Note}

This trick works not only in English, but also in other languages. However, in order to adapt it, you must respect the same criteria that apply to English.

1. The name of the selected card must be three letters or more, so that it becomes card no. 7 in the pile on the table.

2. The linking preposition (of) must be exactly two letters, so that the selected card moves up to card no. 5 in the pile on the table.

3. The name of the card's suit must be at least five letters, so that the selected card remains card no. 5 in the pile on the table.

In some languages, the names of certain cards are less than three letters. For example, in French "ace" is "as": even if you want to call the ace "one", you get "un", which still less than three letters. Of course you could cheat by removing all the aces from the deck before asking the participant to make his selection of nine cards at random.

In some languages, the linking preposition "of" is not exactly two letters. For example, in Dutch it is "van" and in German "von." Or there may be no linking preposition at all.

In some languages, the names of one or more of the suits are less than five letters. Even in closely related languages, this could be a problem. For example, in Dutch the suit names all have at least five letters; in German three of the four suit names are less than five letters.

Finally, to maintain the story line you will need to find a five-letter word roughly equivalent T-R$\mathrm{U}-\mathrm{T}-\mathrm{H}$ to spell out in the final step. It doesn't have to be exactly the same, but something similar. For example, in French this might be V-R-A-I-E (true) for la vraie carte (the true card). 
If you do adapt the trick to another language, please let me know. I would be very interested in hearing about it.

\section{HOMEWORK: Retrospective to Communication Corner No. 4}

In the preceding "Communication Corner," we saw that learning to use the " $5 \mathrm{Ws} \& \mathrm{H}^{\text {" and the }}$ three acid tests is crucial to significantly improving how well one writes, and by extension how well one speaks in public. You were then asked to apply these techniques in two short exercises. In each exercise, you were shown a brief text, given notes on what may be missing or misleading in the text, then asked to rewrite it. Here you will see what a professional writer did with them.

Bear in mind that these are only examples. There are always various ways to profitably apply the " 5 Ws \& H" and the three acid tests. There is no one right way; however, there is only one wrong way. And that is not to apply them at all.

\section{Exercise 1}

[Original]

Belgian police yesterday raided the Brussels office of Stern and arrested its correspondent in connection with an article he had published about the European Parliament.

[Analysis]

Belgian police yesterday raided the Brussels office of Stern (what is Stern?) and arrested its correspondent in connection with an article he had published about the European Parliament (what was controversial about the article?).

1. Stern is a weekly German news magazine.

2. The article was about suspected fraud in the European Parliament.

[Revision]

Belgian police yesterday raided the Brussels office of Stern, a weekly German news magazine, and arrested its correspondent in connection with an article he had published concerning suspected fraud in the European Parliament. 


\section{Exercise 2}

[Original]

Taking a united stand, the French Government and Muslim leaders Sunday condemned Iraqi terrorists who kidnapped two French journalists in order to pressure France into revoking a law that bans Islamic headscarves in state schools.

Saturday night the "Islamic Army" issued a 48-hour ultimatum on the lives of the two journalists. This set into motion a day of emergency meetings in Paris between President Jacques Chirac, Jean-Pierre Raffarin, the Prime Minister, and Muslim leaders seeking a strategy for dealing with France's first hostage crisis in the Iraq conflict.

As his initial move, President Chirac yesterday sent Michel Barnier, the Foreign Minister, to the region for a first-hand assessment of the situation.

[Analysis]

Taking a united stand, the French Government and Muslim leaders Sunday condemned Iraqi terrorists who kidnapped two French journalists (were the journalists kidnapped in Iraq or France?) in order to pressure France into revoking a law that bans Islamic headscarves in state schools (is this law specific only to Islamic headscarves?).

Saturday night the "Islamic Army" in Iraq issued a 48-hour ultimatum on the lives of the two journalists (is the "Islamic Army" new or has it already been active?). This set into motion a day of emergency meetings in Paris between President Jacques Chirac, JeanPierre Raffarin, Prime Minister, and Muslim leaders seeking a strategy for dealing with France's first hostage crisis in the Iraq conflict.

As his initial move, President Chirac yesterday sent Michel Barnier, the Foreign Minister, to the region for a first-hand assessment of the situation.

1. The kidnappings took place in Iraq.

2. The law bans all religious symbols such as Christian crosses, Jewish scull caps, and Sikh turbans.

3. A week earlier the Islamic Army said that it had killed an Italian journalist in Iraq.

[Revision]

The French Government and Muslim leaders united Sunday in condemning terrorists in Iraq who kidnapped two French journalists and demanded that Paris revoke a law banning Islamic head scarves (and symbols of all other religions) in state schools.

The 48-hour ultimatum on Saturday night from the "Islamic Army," which last week claimed responsibility for killing an Italian journalist, prompted a day of emergency 
meetings between President Jacques Chirac, Jean-Pierre Raffarin, the Prime Minister, and Muslim leaders in an attempt to diffuse France's first hostage crisis in the Iraq conflict.

President Chirac yesterday sent Michel Barnier, the Foreign Minister, to the region to help secure their freedom.

\section{CURRENT HOMEWORK}

As shown above, making full use of the two hot spots in each sentence is one of the quickest, easiest ways of improving your writing. Below are a few exercises to give you some practice. But first a couple of examples:

Example A. Having arrived late to the party, Jane immediately looked for the hostess to apologize.

Example B. The current financial difficulties are well under control, said the company's spokesman.

In these two examples, there is both a "main clause" and a "dependent (secondary) clause." The main clause provides the most significant information the sentence is trying to convey. The dependent clause is there to add useful but less significant information.

In example A, "Having arrived late to the party" is the dependent clause; "Jane immediately looked for the hostess to apologize" is the main clause. In example B, "said the company's spokesman" is the dependent clause; "the current financial difficulties are well under control" is the main clause.

Readers will instinctively notice this difference between the main clause and a dependent clause. Thus, the hot spots at the beginning and end of the main clause are where you should focus your attention.

However, don't be dismissive of the dependent clause. If poorly constructed, i.e. long and rambling, a dependent clause can overshadow the main clause, such that the value of putting key information into the main clause's two hot spots will be largely lost.

For example: Treat the dependent clause with respect. If the dependent clause you write to introduce the main clause or supplement it at the end of a sentence is constructed in an undisciplined and slovenly manner, that is to say, it is unnecessarily long such that it seems to dominate the sentence rather than strengthening the sentence, it can overshadow the main clause such that the value of putting key information into the main clause's two hot spots will be largely lost. 
Enough said.

Now it is your turn. Revise the following sentences to ensure that the hot spots are used to their full advantage.

\section{Exercise 1}

In the presence our company's chairman, the new bioscience research center built at a cost of $\$ 75$ million was inaugurated yesterday.

\section{Exercise 2}

Hillary Clinton fired back at the official Republican Party Twitter account after it asked for her to specify her healthcare plan on Wednesday.

\section{Exercise 3}

I claim to be ignorant and proud of it, but rather than being proud of my lack of knowledge I am proud of recognizing just how much knowledge I lack.

\section{Exercise 4}

(Note: Here is a longer, and therefore more complex exercise. At first glance, the following text may already appear to be fairly well written. However, it could be considerably improved. Use everything you have learned about clear $(C l=E D E)$, concise $(C o=L S)$, dense $(D=P L)$ writing, the "5 Ws \& $H$," the inverted pyramid, and hot spots to make it even better.)

Oxford University has once again petitioned the High Court to protect its buildings and staff from animal rights activists. It is asking that a temporary exclusion zone, in force since last month, be made permanent until a full civil trial on the matter can take place. The "no harassment" boundary prohibits protesters from going within 35 meters of university property.

University officials said that work on its new $f 18$ million bio-medical research laboratory was stopped in July because contractors were being intimidated by animal rights activists. Animal testing to be carried out in the facility would be 98 percent on rodents with the remaining 2 percent on amphibians, fish, ferrets and primates.

\section{About the Author}

Philip Yaffe was born in Boston, Massachusetts, in 1942 and grew up in Los Angeles, where he graduated from the University of California with a degree in mathematics and physics. In his senior year, he was also editor-in-chief of the Daily Bruin, UCLA's daily student newspaper. He has more than 40 years of experience in journalism and international marketing 
communication. At various points in his career, he has been a teacher of journalism, a reporter/feature writer with The Wall Street Journal, an account executive with a major international press relations agency, European marketing communication director with two major international companies, and a founding partner of a specialized marketing communication agency in Brussels, Belgium, where he has lived since 1974. He is the author of more than 20 books, which can be found easily in Amazon Kindle.

DOI: $10.1145 / 3152340$ 